\title{
Cybertherapogy: A Conceptual Architecting of Presence for Counselling via Technology
}

\author{
Ebrahim Oshni Alvandi
}

Monash University

\begin{abstract}
The growing urge for mental health via telecommunication systems argues for such services to be discussed at the field of human-computer interaction. However, in spite of the research and evidence that express effectivity of telecounselling, details about the transition to computer-mediated environment are still uncharted. "Cybertherapogy” was coined in this regard to build a schema for engaging and creating meaningful therapy experiences during remote sessions. The model labels strategies that mental health providers should include in their services. Cognitive, counselling, and emotional modules were intersected and overlapped to construct the domains of therapeutic presence in cyberspace. This architecture of emotional agency has been synthesised for psychotherapy by the ongoing concepts and theoretical foundations of presence study and electronic learning engagement. It is believed that the model will enable therapists to facilitate their remote, professional engagement with clients and help design administrative tactics for adequate therapy services.
\end{abstract}

Keywords: Telepresence; Therapeutic Presence; Cyberpsychology; Telecounselling; Emotional Agency; Virtual Reality

\section{INTRODUCTION}

Genuine healing responsiveness is provided by securing the sense of "being willing and intent on approaching and connecting to the present moment of clients, with open readiness to receive what is there without prejudice or expectation”(Geller, Pos, \& Colosimo, 2012, p. 9). This sense which is called therapeutic presence is initiated in face-to-face sessions by observing the clients, seeing their bodily reactions, listening to their mental problems and responding in therapeutic manner (Geller \& Greenberg, 2012, p. 59). However, such preliminary conditions for an effective therapeutic presence can be impaired during computer-mediated communication (CMC). Behavioural and non-verbal cues which are important for therapy purposes are reported with reduction in technology-based communication or CMC might not be simultaneous (Walther, 2011; Walther \& Tidwell, 1995). For instance, text messaging is being offered by providers as a successful mode of delivery for mental health care that lacks physical presence, and unlike in office sessions, can build asynchronous connection (see, for example,Pelling, 2009; Robinson \& Serfaty, 2008). Meanwhile, the presence of users is less embodied in cyberspace and thus a shear informational interaction with a partner cannot guarantee on itself a unified sense of therapeutic presence (Tu \& McIsaac, 2002). Thereby it seems to be explainable that responsiveness if defined in association with the presence of counsellors including psychotherapists might not be assured when telecommunication technologies are used. Even so with this initial induction, there are no attempts, to the best of the author's knowledge, which has explored therapeutic presence as a concept when mental health service is provided via technology. Reserving experimental requirements as future loadings, the current study aims to define how e-counselling / cybertherapy ${ }^{1}$ presence could be conducted in technology-based environment. The following suggests a framework and discuss the dimensions for this purpose.

\footnotetext{
${ }^{1}$ These terms will be used interchangeably. However, cybertherapy will be employed specifically when healing is at the core of the e-counselling practice.
} 


\section{CYBERTHERAPOGY: A MODEL FOR COUNCELLING PRESENCE}

The similarity of servicing environment of health care with other activities postulates the ongoing model. (Miclea, Miclea, Ciuca, \& Budau, 2010). On the basis of some e-learning models such as the Inquiry Model of CMC (Garrison, Anderson, \& Archer, 1999) or the Cybergogy for Engaged Learning Model (Wang \& Kang, 2006), we can establish how the servicing nature of e-counselling (including e-mental health) looks similar to e-learning purposes. Initially, it is regarded that e-counselling servicing targets consultation or psychotherapy by distance as like as e-learning which was aimed for the accessible online education. In other words, online counselling environment and online teaching classes have almost the same informational nature of communication and both services look after remote therapeutic and learning outcomes, respectively. The second syllogism is suggested by e-learning programs that seek to ease the educational communication between teachers and learners. As such, e-counselling programs wish to provide effective therapeutic interventions between counsellors and clients.

The similarities are striking but they are not enough to lay out the structure of e-counselling. To build a conceptual model that better describes therapeutic presence for e-mental health there is another substantial analogy that relates to the ways the tasks and methods of e-learning and e-counselling are performed. Elearning literature suggests that teaching capability during telepresence should be provided by teachers' rendered skills. In the similar way counsellors who use meditated environments or assistant automated therapists have to represent counselling capabilities. Specifically, employing the knowledge from relational dyad of teaching-learning can assist us in resembling the interactive communication and relational dyad of treatment-recovery between online pairs of counselling.

However, several factors have to be elucidated when a dyadic interaction between CMC pairs is sought. On the one hand, visibility is discussed the main admitting level of presence (Wang and kang, 2006). This level is discussed in e-learning a key that associates with the visibility of teaching pairs or sensibility of their actions, which, in turn, is urged more in mental health care. However, visibility is not granted if an online environment (including Virtual Reality) does not provide comprehensive levels through which the community in learning and teaching engage with each other (IJsselsteijn, 2002). It is said that visibility is not a simple measure that can warranty a meaningful interaction. Highlighting its role, a union of cognitive, social, and emotive levels is supposed to realize and qualify online learning more engaged. Research has reportedly supported the importance of this implemented levels for online interaction, social networking, and has confirmed the accuracy and efficacy of the hypothesized causal relationships among online presence and learning (For more detail see: Garrison et al., 1999; Kang, Kim, \& Kang, 2008; Kang, Kim, Choi, \& Park, 2007; Kang, Kim, \& Park, 2007; Shea \& Bidjerano, 2009).

Likewise, e-counselling or cybertherapy sessions need to operate modulated therapeutic presence to cultivate clients' problems and detect their mental disorder. This is argued because the correlation of visibility and therapy process is granted as the significant level of therapeutic occurrence in computer-mediated environment (CME). In addition to this, computer-mediated sessions should desire effective therapeutic responsiveness by engaging users of CME to understand the spiritually of their communication; this understanding will not be achieved if not be similar to an in-person counselling session that is sought by emotional and cognitive engagement with clients (Geller \& Greenberg, 2002, 2012; Geller, Greenberg, \& Watson, 2010; Robbins, 1997). Reserving these assumptions, the domains of the modules that are thought to engage therapists-clients together through CME are explored below (See Figure 1). 


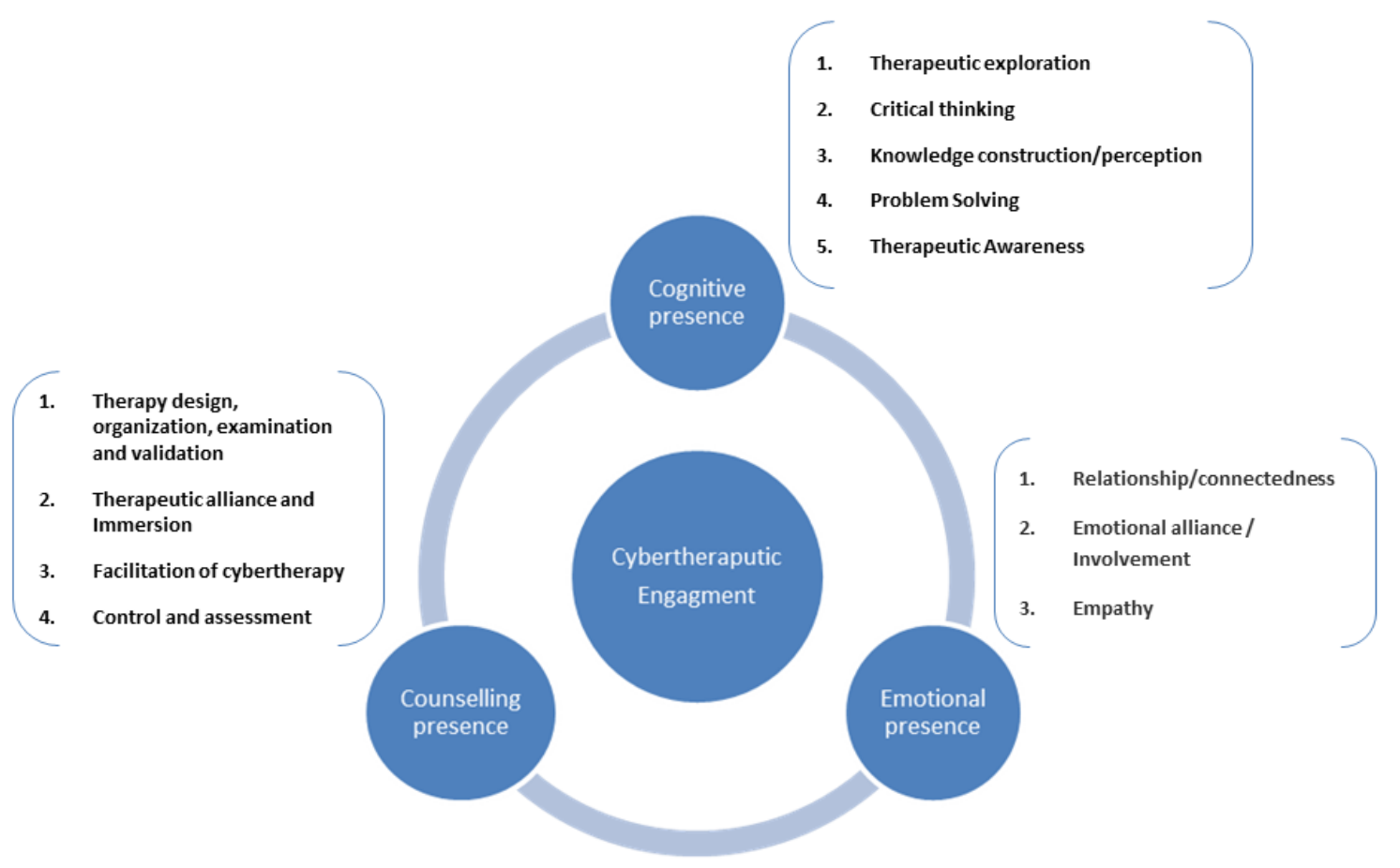

Figure 1. Cybertherapogy: Modules of Therapeutic Presence via Technology

\section{COGNITIVE MODULE OF COUNSELLING PRESENCE}

The physical interaction per se does not guarantee clients and counsellors be engaged in consultation or psychotherapy with a meaningful manner and high level of understanding. Meaningful therapeutic interaction is a by-product of cognition that comes out as an inherent junction to bind both perceptual and cognitive actions of interactivity (Fodor, 1983). In this spirit, cognitive module of presence is proposed the first to achieve a sound interactivity in terms of e-counselling / cybertherapy (figure 1). It is interpreted as the degree to which CME dominates over the real environment as the basis for therapeutic thought (Nunez \& Blake, 2001). In other words, interactivity in CME would be sound whenever interactors understand and perceive each other mutually, judge and also reason about communicated objectives with remarkable satisfaction. However, it is necessary to justify (1) what cognitive module provides for therapeutic presence and (2) how the module is presented during cybertherapy session.

In regard to the first inquiry, cognitive presence constructs typically a body of knowledge for e-counselling / cybertherapy provider that is regarded a practical rational inquiry (Garrison et al., 1999). This rational inquiry demonstrates critical thinking that provides counselling interactants a meaning construction channel per a sustained and intimated (healing) communication (Cobb, 2009). In other words, while cognitive presence is pinned to counselling process, counsellors can critically explore what CME offers to the intervention. They also can interpret the digital communication and expect what communicated verbal and nonverbal cues carry towards therapeutic aims. Therefore, the module enables the counsellors to end up with one or hybrid effective counselling methods to be employed and assists them in monitoring the outputs to reach a logically certain, positive conclusion.

Regarding the second inquiry, cognitive module of presence is practiced by utilizing communication skills (Kreijns, Kirschner, Jochems, \& Van Buuren, 2011) and is experienced via perceptual motor loop (IJsselsteijn, 2002; Nunez, 2007). That says, multisensory and conceptual apparatus involved in communication builds action-based perception, focused attention/awareness, and the integration of reasoning and problem solving. However, we wish to stress that - recognizing psychological problem and providing consultation / therapy 
from only embodied cues can lack a cognitive component because body movements or facial expressions of clients produce only body state information of affects or mental disorders, but nothing more about the meaning of the action or behaviours in clients. Therefore, bodily information can be a dependent variable to investigate the cognition of mental states such as emotions (Zhang, Yu, \& Barrett, 2014), but cannot be considered independent variable in cybertherapy conditions as pertain to be inhibited for many reasons (e.g. less therapeutic alliance, disrupted cyber interventions). Also, nonverbal cues that are reduced or blurred through computer-mediated delivery conditions need to be exposed by virtue of elaborated cognitive capacity to avoid any interference with remote environment and therapeutic tasks. Therefore, any facts and ideas transmitted in online therapy session stands on the experience of communicated concepts, taken actions and deliberations, rather than relying on the expressed bodily cues (Kanuka \& Garrison, 2004).

Presenting cognitive module of presence, however, should be propounded with a procedural way of practicing. Based on an analogy drawn from e-learning studies, the cognitive module could be identified with four phases in counselling / cybertherapeutic inquiry process (Garrison, Cleveland-Innes, \& Fung, 2010) (see figure 1). The exploration phase is the first phase that can define what is a problem or task. The second is the critical thinking phase that explores relevant information/knowledge over the problem or disorders. In the third phase that is called knowledge construction, ideas for the practice are integrated and (healing concepts are clarified; and, finally, during the problem solving phase, plausible methods, supports or cares are designed and practiced consciously by online counsellors / cybertherapists.

These phases, according to Wang and Kang (2006), will largely be aligned by following the information level of therapeutic interaction. There stages are introduced for this purpose. In information acquisition stage, current/prior knowledge of personal and social states are assessed to find useful information for the counselling question. Counselling pairs in this stage explore their situations and then integrate the information to give an appropriate organizational reflection (Kanuka \& Garrison, 2004). In information transformation stage, relevant and appropriate information of intervention (e.g. history of mental disorders and possible supports) are communicated between parties to direct consultation towards a figured goal. Collaboration, management and engagement are phased between counselling pairs over this stage. The stage of counselling knowledge construction is the third one that coaches counsellors and clients to improve and optimize their therapeutic alliance and requirements (Martin, Garske, \& Davis, 2000). This stage of cognitive development conceptualizes therapeutic information so that mental problems and troublesome situations can be perceived and monitored appropriately (Kanuka \& Garrison, 2004). The therapists who acquire such constructive knowledge of therapy could in turn enhance their controlling capability of therapy process. They can judge about their reflection to emotional experiences of clients and assess accuracy of consultation. This stage also informs about the actions that can be taken to cover new mental problems, the similar therapeutic context and new circumstances of communication.

Beyond the sensory motors and informational stages, exchange of empathic information is proposed the fourth stage to the information level of cognitive presence (Hayes \& Vinca, 2011). Psychotherapy literature suggests empathetic relationship between client and therapist a salient factor of therapy. Here, cognitive empathy turns into a key matter since that can assist in therapeutic reasoning. In other words, cognitive empathy is a component of the cognitive module that involves an intellectual comprehension of clients' inquiry or mental disorders. This empathy also weights inferring ability of counsellors by enabling them to diagnose psychological states of clients and adopt the remedial perspectives (see for review: Davis, 1996). However, this analytical ability overlaps with the level of awareness in counsellors. According to Hoffman (1984), counsellors will emphasize authoritatively with clients when they are capable to recognize concurrently one's self and client's selves. They should also be skilful in differentiating one's own and client's emotional states consciousnessly; otherwise those of counsellors who empathize unconsciously with clients may not understand the thoughts and feelings of clients and that may end with difficulty in therapeutic process (Baron-Cohen \& Wheelwright, 2004).

\section{COUNSELLING MODULE OF PRESENCE}

Counselling presence has a strong association with professional skills of care providers. Literature review introduces, for example, nursing presence an important factor for qualitative nursing care services (Doona, 
Haggerty, \& Chase, 1997; Melnechenko, 2003; Minicucci, 1997). Easter (2000) highlights the nursing a key mode to provide care for the sick as long as a nurse is present to a patient in an authentic professional relationship. It is also the similar thought in the work by Finfgeld-Connett (2005). He suggests that health supports are provided professionally when nursing practices are conducted in the presence of nurse-patient dyad.

Although presence is a recent attended concept in in-office psychotherapy (Geller \& Greenberg, 2002, 2012; Geller et al., 2010; Geller \& Porges, 2014; Geller et al., 2012; Greenberg \& Geller, 2001), it has been discussed that psychotherapy would be ended effectively and the relationship between counselling pairs would be productive when therapists show themselves present in the therapy sessions (Rogers, 2000). According to Anderson (2007) who declares that nursing presence establishes a long-term relationship between the patient and nurse, counsellors' presence could form a lasting communication between them and clients. This kind of presence is also considered important because a counsellor who presents a good level of such presence can easily teach the clients self-care methods, or coach them control their concerns and encourage them to behave positively (Finfgeld- Connett, 2008). However, the development of a comprehensive and coordinated concept of counselling module needs to endorse some characteristics which are discussed below.

First and foremost, the physical presence of counsellor is inquired a necessity in the therapy sessions that is generally seen as "being immediately present to his client, relying on his moment-to-moment felt experience in the relationship" (Rogers, 1989, p. 16). Nonetheless, unlike in-office sessions of psychotherapy, CME disembodies the presence of counsellor as well as clients. This argumentation is expressed important when technology change the border of presence in comparison to in-person centred therapy. For instance, asynchronous text-based therapy, standalone versions of care services (e.g. MoodGYM) or podcasts exclude therapists' presence as a function of therapy process. Virtual reality, although can employ avatars to animate a counsellor, yet portrays a dummy feeling of humans. Therefore, the physical appearance of counsellors should be worked to represent an optimal understanding of a human being in the real world.

In spite of the fact mentioned, the multi-layered counselling module should not be limited to a use of counsellors' selves or their physical presence. In other words, counselling presence is not attuned to just bodily awareness as a tool to understand clients in CME. Rather, it is declared that clients who uses technology will receive therapy services if (1) therapy is acted far more than an inward connection with clients' body and (2) there is an improved mediated access to counselling services (Coman, Burrows, \& Evans, 2001). Regarding the first condition, some set of conditions encapsulates administrative and interactive steps that has to happen as in in-office setting (Granick, 2011; Afolabi, 1992). On the side of administrative steps, any kind of counselling designs, treatments and organization of therapy should be optimized for technology-based environment. It is to say that counselling presence in CME including human-based therapy process or programmed platforms such as apps or MoodGym has to satisfy the standard requirements of therapy by being transparent in communication, giving a high feeling of security, privacy, confidentiality and accuracy, warranting mutual sense of dignity, having strong role models and a sense of self facilitate therapy (Ackerman \& Hilsenroth, 2003; Denkowski \& Denkowski, 1982; Anderson, 2007; Doona et al., 1997; Kostovich, 2012).

In committing to a true sense of presence, Finfgeld-Connett (2005) believes strongly in the role of proficiency over the therapy methods. He thinks that such expertise can develop online therapeutic relationship by increasing the understanding level of clients about the problems that have been instilled to therapy sessions. For example, it is suggested that cybertherapists need to be process-oriented, be willing to risk, work for small gains, help clients resolve the past through the therapy, have clarity about human development, respect clients' own power to change, respond to clients' clues, and enhanced by the clients' growth (Pemberton, 1977). Also, clients should perceive their therapists as present with a good established serving and communication skills as they have been assigned the key for productive therapeutic alliance (Geller et al., 2012). In the absence of physical information, it is also discussed that clients may disclosure their problems or thoughts during cybertherapy more than face-to-face conditions, provided that cybertherapists establish not a netiquette from the beginning of the telecommunication, but a collaborative monitored environment.

Regarding the second condition of counselling presence via technology, Table 1 enlists some other key properties. For example, human or assistant therapists need to clarify understandability and comprehensiveness of mediated communication by removing unclear or ambiguous information, messages, and 
paraphrase/summarize accurately the concerns of the client in their own short words. As this point, the experience level in telecommunication tools such as messaging or hardware contribute to the integration of presence modules (Minicucci, 1997; Stein \& Lambert, 1984). Meanwhile, it is an indispensable need to be trained to interact with clients in the lack of human interaction (Hutchison \& Gerstein, 2012). Proficiency in verbal and nonverbal interaction will thus boost the expectancy level in computer-mediated therapy.

Table 1. General attributes of counselling presence

\begin{tabular}{lll}
\hline Listening & Silence & Openness \\
Authenticity & Humor & Trust \\
Understanding & Compassion & Respect \\
Commitment & Vigilance & Affirming \\
Reassurance & Sharing & Coaching \\
Touch & Confidence & Competence \\
Nonabandonment & Self-awareness & Continuity \\
Conscience & & \\
\hline
\end{tabular}

On the other hand, computer-mediated counselling should be a realistic experience for the client's healing or consultation process. Counsellors or assistant therapists must insure the conscious and professional sensation of therapy when the client's expresses his/her mental problems, feelings, malaise or moods (Simone, 1992). Furthermore, clients' experience of the therapists and therapy has a greater impact on the realism of therapy (Geller, 2012). Therapeutic presence via technology has to enable a client to feel fully perceived and understood. Realism is also achieved when technology adjusts every aspects of human-computer interaction such as providing user-friendly interface and high quality medium of communication. Finally, to satisfy realistic counselling presence in technology, it is thought that the therapy process requires to be organized earlier. The client needs to be contacted and arriving into the therapy intervention has to be planned in advance; this case has also association with the administrative section of acting steps.

\section{EMOTIONAL MODULE OF COUNSELLING PRESENCE}

Indeed, a positive relationship between client and counsellor can build a significant base to have a therapy be accomplished well (Norcross, 2011). Here, grounding the vital role of emotions on their social engagement is the main argument for independent emotional module of counselling presence. Short, Williams, and Christie (1976, p. 65), for instance, had provided a classical characterization of social presence asserting that therapeutic presence is realized via interpersonal communication. Such interaction, however, is formed by social associations, intimate connections, or affiliations between present communicators that can be highlighted in bold for healing engagement. Communicators incorporate much of emotional information as a means to perceive the psychological status by vast majority of daily conversations. This interaction entails the exchange of affective information about the pairs opinions, preferences and evaluations, which in turn indicate that affects dominate social interaction, or they are the major independent currency in which social/therapeutic relationships are transacted (Zajonc, 1980).

Emotions are also major independent determinants of presence because the users of telecommunication technologies 'feel' their presence. In other words, it is important in an affective interaction to know what sorts of feeling are being perceived in the speakers. Such feeling, indeed, relates to the emotional experience of individuals involved in CMC and certainly is different than perceiving the physicality of communicators or the perception of being present (Alcañiz, Baños, Botella, \& Rey, 2003; Colosimo \& Pos, 2015; Rey et al., 2004; Riva et al., 2007). For instance, people who are engaged in an online task can increase only the intensity of sociality of communication and thereby influence likely some slight behaviours (e.g. smiling) as yet the communicators may not impress the emotional involvement among each other. Therefore, emotional relationship to somebody is suggested a different independent factor than experiencing what a communicator says when he says that "... it is much less important for us to know whether someone has just said 'You are a friend' or 'You are a fiend' than to know whether it was spoken in contempt or (behaved) with affection" (p.153). On the other hand, perception of emotions or affective expressions can influences independently the 
degree of awareness over the other communicator's emotional states and their reality (Alvandi, 2017a, Manstead et al., 2011, p. 159). For instance, Riva et al. (2007) shows that individuals feel being in the virtual environment greater where they perceive emotions present or expressed explicitly.

The last but main argument in support of independent emotional module of presence arises when emotions affects professional life. Again referring to knowledge from E-learning studies, it has been shown that any negative change in the emotions of e-learners can decrease the efficacy in learning or teaching process (Kang, Kim, Choi, et al., 2007; Kang, Kim, \& Park, 2007; Lehman, 2006). Similarly, an affective counselling presence requires assessing the level of emotional proximity with clients (Huang \& Alessi, 1999; Rey et al., 2004). In this regard, Geller and Greenberg (2012) found that emotional disorders will be attuned if the client's emotional presence was perceived by therapists highly detailed and reflective. Thus it is a concern that mental concerns can be inhibited where therapists have not a good understanding of emotions in artificial environments (Alvandi, 2017a). Further, affective responsiveness, high level of emotional experience and emotional behaviours of therapy pairs are the key intensifiers in therapeutic process (Fosha, 2001). They propose a great degree of emotional relatedness in therapy session (Dillon, Keogh, \& Freeman, 2002). However, unlike social presence that shares the facts of social life, motives and also intentions of communicators (Manstead et al., 2011), emotional presence in clients incorporates their facts of desires or mental concerns. Due to the healing requirements, counsellors are responsible in managing and orienting expressed emotions. Research suggests uncomfortable feelings due to the client's threatening or challenging tendencies cause the ineffective responses that are displayed by counsellors (Hayes, Gelso, \& Hummel, 2011; Myers \& Hayes, 2006). Therefore, it is suggested that emotional presence of counsellor is an important independent source of information about the clients' personal behaviours; clients, for instance, disclose more of their emotional concerns when counsellors are emotionally present in therapeutic communication (Batten and Santanello, 2009).

\section{Components of emotional presence in remote counselling}

As discussed, emotional module is not a single modality. In line with the definition of emotional intelligence, Table 1 locates three components of the module that has to be implemented in CMC: 1 ) feeling emotions that associates with perception and identification of emotions in counselling intervention (Alavndi, 2017b), 2) expressing emotions which informs counsellors about clients' emotional disorders, 3) managing emotions that is a component to assists (mental health) professionals for regulating and conducting emotional supports effectively, and by using emotional information they can facilitate thinking process for better care (see for more details: Mayer, Caruso, \& Salovey, 1999; Mayer, Roberts, \& Barsade, 2008; Mayer \& Salovey, 2007; Salovey, Brackett, \& Mayer, 2004; Salovey \& Mayer, 1989). However, the sense of emotional presence is intensified by means of other high level features of communication such as connectedness, alliance, empathy, intimacy and immediacy that are discussed below.

Table 2: Components of emotional presence

\begin{tabular}{ll}
\hline Main Components & Subcomponents \\
\hline \multirow{2}{*}{ Feeling emotion } & Comfortableness \\
& Security \\
& Interest \\
\hline \multirow{2}{*}{ Expressing emotions } & Freedom \\
& Diversity \\
& Clarity \\
\hline \multirow{2}{*}{ Managing emotion } & Flexibility \\
& Activeness \\
\hline
\end{tabular}

\section{Connectedness}

Connectedness, a fundamental human motivation (Baumeister \& Leary, 1995, p. 497), describes the basic principle of relationship between users (Townsend \& McWhirter, 2005). General type of connectedness associates with productive relationship when a user is actively involved with another user, object, group, or 
environment, and that involvement promotes a sense of comfort, wellbeing, and anxiety-reduction (Hagerty, Lynch-Sauer, Patusky, \& Bouwsema, 1993). Emotional connectedness, in particular, is referred as a degree of affective relationship to which pairs feel actively involved with each other's emotions or objects in a CME (Rispens, Greer, \& Jehn, 2007). In a nutshell, emotional connectedness is regarded the capability that aims to balance the exchange of feelings in users and form a bond among them based on a good understanding and appreciation of affections.

Emotional connectedness, however, is distinguished from social (Lee, Draper, \& Lee, 2001), task and cognitive senses of connectedness (Rispens et al., 2007). Firstly, this component is differed from the social part of connectedness because social connectedness is characterized as a structure representing regularities in patterns of interpersonal relatedness in a virtual environment (Baldwin, 1992). In other words, social aspect of connectedness measures in a general way how users come together and interact within CME. While in the course of e-counselling or cybertherapy, emotional connectedness should represent the affective relatedness and emotional understanding that counselling pairs have; naturally such connectedness is experienced when pairs are actively involved in communicating, perceiving and expressing each other (Rispens et al., 2007). Secondly, the emotional connectedness is incompatible with the task connectedness. In therapeutic language, the task connectedness that associate with counselling module of presence only represents the perception of clinical responsibility of perceived pairs who are actively involved with therapy and one another to accomplish their therapeutic tasks. Finally, emotional connectedness is unlike cognitive connectedness between pairs. What cognitive connectedness should offer is representing analytical relativity through psychotherapy process. This aspect of connectedness, in fact, should be placed in cognitive module of presence where pairs speak about the therapeutic knowledge and are actively involved in accessing and employing the systematic therapeutic information.

Depending on the dominant counselling viewpoint, emotional connectedness could be regarded a function. On the basis of the literature (Baldwin, 1992; Townsend \& McWhirter, 2005), this connectedness is well constructed within a progressing relational connection if dependence, engagement, loneliness, attachment, and affiliation were understood well between telecommunicators. Also, to load the emotional connectedness authoritative can recall consciously the previous emotional content of counselling interactions that have been took place with clients. Analysing the clients' psychological status can be another strategy for satisfied emotional connectedness. That said, counsellors can trigger the conceptualization of the clients into the discussion when those clients brought in their emotional problems to the counsellors' attention.

Emotional connectedness has also a deep influence on psychotherapeutic cooperation if it is functions regarded. In line with Bordin (1979), a review by Ackerman and Hilsenroth (2003) shows that positive connectedness felt early in the therapeutic relationship associates with "therapist training, consistency, nonverbal gestures (e.g., eye contact, leaning forward), verbal behaviours (e.g., interpretation, self-disclosure), and the maintenance of the therapeutic frame” (p.4). It has also well reviewed that influential emotional connectedness in therapy can increase and develop patient's relationships with counsellors (Townsend \& McWhirter, 2005). In their review, Townsend and McWhirter (2005) declare that mental health professionals would serve their patients further by cultivating within themselves a strength-based attitude as well as a nonjudgmental observational stance toward their clients' emotional connectedness. It has also been suggested that positive connectedness explores a good sense of therapeutic presence during face-to-face psychotherapy (Geller \& Greenberg, 2012). It is experienced when both therapy partners feel other's emotions, or concerns are conveyed properly to the partner (Biocca \& Nowak, 2001).

\section{Emotional alliance}

Emotional alliance is another sub factor suggested here significant for emotional module of presence. This factor is believed something more than connectedness because emotional alliance is a strong predictive indicator of emotional engagement (Johnson, 2012). It deals with the mutual emotional link, trust, and warmth between the counselling interactors (Sussman, 2004). and falls beyond the rational considerations of therapeutic relationship (Johnsson \& Stenlund, 2010). This factor is fortified by emotive dimensions of therapy and is called a cognitive function for a higher-order emotional involvement (Wirth et al., 2007; Wirth et al., 2012). To put it in another way, understanding and analysing affective side of communication, describing and exploring emotional disorders are the results of this component. 
The literature from face-to-face studies suggests that cognition, feeling and behaviours in clients relate directly to emotional alliance. For instance, emotional alliance can enhance family relationships (Martin et al., 2000). It has also found that the therapeutic outcomes improve where there is a well-conducted emotional alliance (Cook \& Doyle, 2002; Hanley \& Reynolds, 2009). Emotional alliance is also found effective in online counselling. For example, Posttraumatic Stress Disorder is decreased when there is a positive alliance between client and therapist via videoconferencing or telephone (Germain, Marchand, Bouchard, Guay, \& Drouin, 2010; King, Bambling, Reid, \& Thomas, 2006; Simpson \& Reid, 2014). However, emotional alliance goes to a far greater extent for presence by the quality of the professional but affective relationship between the therapist and client (Geller \& Greenberg, 2002, 2012). Appropriate emotional involvement may produce mutual understanding, affective and therapeutic consequences. The consequences of therapeutic behaviours such as selecting particular methods of therapy and relevant actions will also be warranted when psychotherapists engage emotionally with their clients (Wirth et al., 2012). Emotional alliance also oversee the way psychotherapists respond to affective communication from the client (Johnsson \& Stenlund, 2010). In a nut shell, counselling pairs will feel mutually connected when they emotionally awarded and perceived within CME.

\section{Empathetic Relationship}

It is a thought that presence of counsellor does not mean only an ability to infer emotional states, adopt the perspective of clients or feel related to them (Andréasson, 2010; Davis, 1996). Rather, counsellors have to empathise with the clients. They need to be sensitive and understand totally the emotional states of their clients (Hassenstab, Dziobek, Rogers, Wolf, \& Convit, 2007). Emotional empathy is, thus, a very much significant component in emotional module of therapeutic presence.

To empathize with clients and make an engaged emotional presence, while cognitive empathy enables counsellors comprehend clients' mental disorders (Hoffman, 1984; Smith, 2006), emotional empathy provides them the ability to react emotionally (e.g., compassion) to the clients' concerns (e.g., sadness) and provide a vicarious emotional support to the perceived emotional experience of clients (Mehrabian \& Epstein, 1972). In other words, counsellors who are elaborated in taking emotional empathy online can dispense a good emotional corresponding to clients' needs. Further, the exploration of emotional empathy would aid the counsellors to develop a specific competency in delivering the emotional reactions and satisfying the emotional alliances (Hassenstab et al., 2007). There will also be empathic attunement with the clients when a counsellors resonate with the clients' experiences (Johnson, 2012). As expected, emotional empathy can further influence the online treatment outcome (see: Elliott, Bohart, Watson, \& Greenberg, 2011; Kurtz \& Grummon, 1972).

\section{Higher Order Immersion}

The engagement of users should also be invited in the studies of mental health via virtual reality. That would not only account the relativity and depth of physical and non-physical receptivity for counselling presence via technology, but also satisfy emotional module of their presence. Two elements, thus, are called from CMC research. Initially, intimacy of interaction is questioned which is beyond the physical proximity or body movements of counselling pairs. When considered, the level of intimacy can be rated by trust, association, familiarity, self-disclosure and affiliation between counselling interactors (Burgoon, Guerrero, \& Floyd, 2010; Granick, 2011).

On the other hand, there is immediacy which is "the ability of the counsellor to get the client to focus on what is currently going on in the counselling relationship”(Afolabi, 1992, p. 34). Individual feedback, personalized exchanges, using inclusive language and concerns for others are elements of conducting immediacy. Immediacy is also marked by bodily behaviours (Mehrabian, 1981; Wiener \& Mehrabian, 1968). For instance, people of counselling parties realize the immediacy with mutuality smile, nodding heads, and leaning forward (Ambady \& Rosenthal, 1998). In particular, observing others' relationship, gazes and eye contact communicates immediacy which should be regarded in videoconferencing-based therapy (Manstead, Lea, \& Goh, 2011). It is well documented that facial expressions provides and regulates information for social interaction, empathy, emotional behaviours (Kleinke, 1986; Mathews, Fox, Yiend, \& Calder, 2003; Newton, Burgoon, \& Cahn, 1990). In addition to facial cues, voice intensifies reactions to emotional stimuli that become 
important functioning factors of interpersonal interaction and immediacy which has to be accounted with details in audio-based therapy (Berenschot et al., 2013; Minzenberg, Poole, \& Vinogradov, 2006). Clients or counsellors can also behave gestures, give personal examples, address the other pair by his/her name, ask questions, discuss, encourage, feedback, and avoid tense body positions to promote immediacy. Finally, affective language should be inspected far more as it provides key semantic clues in terms of emotional disorders. It has been repeated that emotional prosody including direct and indirect affective conversation maximizes the understanding level of severity in emotional expressions in text-, audio-and video-based therapy (Pell, Jaywant, Monetta, \& Kotz, 2011; Rigoulot \& Pell, 2012; Schwartz \& Pell, 2012).

Eventually, nonverbal immediacy seems a key factor to support clients to stay longer in the therapy process via technology. However, immediacy as well as intimacy can be influenced negatively if behavioural cues are misunderstood (Hutchins, 2003). Manstead et al. (2011, p. 168) demonstrate that the lack of mutual eye contact in users (importantly in avatars), for instance, can cause unawareness in the emotional expression through the gaze, which is 'a key difference from co-present interaction". Meanwhile, differences in the quantitative and qualitative transmission of nonverbal cues can contribute to the degree of nonverbal immediacy. In other words, due to the changes in the quality and quantity of immediacy and intimacy in CME, it seems that therapeutic presence via technology can be impacted negatively so that should be attended carefully by providers (Cobb, 2009).

\section{CONCLUSION}

The current curiosity aimed to undress the concept of presence reflected in mental health care when it is practiced via computer-mediated environment. Cybertherapogy was introduced here a framework to provide an engaged counselling practice by reflecting a systemic approach to e-counselling or cybertherapy. On the basis of e-learning and telepresence studies, it is argued that therapeutic telepresence could not be achieved via physical or social appearances of users. Due to categorical processing within therapy, cognitive, counselling, and emotive domains are identified as critical modules in approaching the presence in cybertherapeutic environment. Depending on the research cited and argumentation provided, the components of presence are believed that can grant counsellors the ability to discern what is important for the clients.

However, the current model is the very first theoretical attempt and is an initial mapping of the territory for therapeutic telepresence. No study is found that has investigated the mediated sense of presence and whether that can generate emotional-therapeutic facilitation, improvement or inhibition in e-mental health / computermediated therapy. Presence in cybertherapy as well as its equivalent discussion from e-learning discipline is quite primitive and needs more consideration to provide an assessing and measuring instrument (ClevelandInnes \& Campbell, 2012; Kang, Kim, \& Park, 2007). There is also a need for further systematic, empirical investigations which focus on the facilitation of emotional agency and therapeutic development in different computer mediate conditions. Studying the model in different conditions of delivery (e.g. text messing, videoconferencing, and virtual reality) will also enable experts to refine pragmatically the concept of presence and its modules for psychotherapy via technology.

\section{REFERENCES}

Ackerman, S. J., \& Hilsenroth, M. J. (2003). A review of therapist characteristics and techniques positively impacting the therapeutic alliance. Clinical Psychology Review, 23(1), 1-33.

Afolabi, M. (1992). The application of counselling concepts to interviewing in reference services. Library Review, 41(4).

Alcañiz, M., Baños, R., Botella, C., \& Rey, B. (2003). The EMMA Project: Emotions as a determinant of presence. PsychNology Journal, 1(2), 141-150.

Alvandi, E.O. (2017a). Emotional Agency in Telecounselling: A Cognitive Model (Unpublished Doctoral dissertation). Monash University, Melbourne, Australia, Retrieved from https://figshare.com/articles/Emotional_Agency_in_Telecounselling_A_Cognitive_Model/4644799

Alvandi, E.O., Van Doorn, G., \& Symmons, M. (2017b). Emotionality in Computer-Mediated Environments: Analyzing the Emotional Content of Psychotherapeutic Communication. Journal of Interaction Science. 5, 2.

Ambady, N., \& Rosenthal, R. (1998). Nonverbal Communication. In Friedman HS (Ed.), Encyclopedia of Mental Health (Vol. 2). New York: Academic Press. 
Anderson, J. H. (2007). Nursing presence in a community heart failure program. The Nurse Practitioner, 32(10), 14-21.

Andréasson, P. (2010). Emotional Empathy, Facial Reactions, and Facial Feedback. Uppsala University.

Argyle, M., \& Dean, J. (1965). Eye-contact, distance and affiliation. Sociometry, 289-304.

Baldwin, M. W. (1992). Relational schemas and the processing of social information. Psychological bulletin, 112(3), 461.

Baron-Cohen, S., \& Wheelwright, S. (2004). The empathy quotient: an investigation of adults with Asperger syndrome or high functioning autism, and normal sex differences. Journal of autism and developmental disorders, 34(2), 163-175.

Batten, S. V., \& Santanello, A. P. (2009). A contextual behavioral approach to the role of emotion in psychotherapy supervision. Training and Education in Professional Psychology, 3(3), 148-156. doi: 10.1037/1931-3918.a0014801

Baumeister, R. F., \& Leary, M. R. (1995). The need to belong: desire for interpersonal attachments as a fundamental human motivation. Psychological bulletin, 117(3), 497.

Berenschot, F., van Aken, M. A., Hessels, C., de Castro, B. O., Pijl, Y., Montagne, B., \& van Voorst, G. (2013). Facial emotion recognition in adolescents with personality pathology. European child \& adolescent psychiatry, 1-8.

Biocca, F., \& Nowak, K. (2001). Plugging your body into the telecommunication system: Mediated embodiment, media interfaces, and social virtual environments. Communication technology and society, 407-447.

Bordin, E. S. (1979). The generalizability of the psychoanalytic concept of the working alliance. Psychotherapy: Theory, Research \& Practice, 16(3), 252.

Burgoon, J. K., Guerrero, L. K., \& Floyd, K. (2010). Nonverbal communication. Boston, : MA: Allyn \& Bacon.

Choi, Y. K., Miracle, G. E., \& Biocca, F. (2001). The effects of anthropomorphic agents on advertising effectiveness and the mediating role of presence. Journal of Interactive Advertising, 2(1).

Cleveland-Innes, M., \& Campbell, P. (2012). Emotional Presence, Learning, and the Online Learning Environment. International Review of Research in Open \& Distance Learning, 13(4).

Cobb, S. C. (2009). Social presence and online learning: A current view from a research perspective. Journal of Interactive Online Learning, 8(3), 241-254.

Colosimo, K. A., \& Pos, A. E. (2015). A Rational Model of Expressed Therapeutic Presence. Journal of Psychotherapy Integration, 25(2).

Coman, G. J., Burrows, G. D., \& Evans, B. J. (2001). Telephone counselling in Australia: applications and considerations for use. British Journal of Guidance and Counselling, 29(2), 247-258.

Cook, J. E., \& Doyle, C. (2002). Working alliance in online therapy as compared to face-to-face therapy: Preliminary results. CyberPsychology \& Behavior, 5(2), 95-105.

Davis, M. H. (1996). Empathy: A social psychological approach: Westview Press Boulder, CO.

Denkowski, K. M., \& Denkowski, G. C. (1982). Client- Counselor Confidentiality: An Update of Rationale, Legal Status, and Implications. The Personnel and guidance journal, 60(6), 371-375.

Dillon, C., Keogh, E., \& Freeman, J. (2002). It’s Been Emotional”: Affect, Physiology, and Presence. Paper presented at the Proceedings of the Fifth Annual International Workshop on Presence, Porto, Portugal.

Doona, M. E., Haggerty, L. A., \& Chase, S. K. (1997). Nursing presence: An existential exploration of the concept. Research and Theory for Nursing Practice, 11(1), 3-16.

Easter, A. (2000). Construct analysis of four modes of being present. Journal of Holistic Nursing, 18(4), 362377.

Elliott, R., Bohart, A. C., Watson, J. C., \& Greenberg, L. S. (2011). Empathy. Psychotherapy, 48(1), 43.

Finfgeld-Connett, D. (2005). Telephone social support or nursing presence? Analysis of a nursing intervention. Qualitative health research, 15(1), 19-29.

Finfgeld- Connett, D. (2008). Qualitative convergence of three nursing concepts: art of nursing, presence and caring. Journal of Advanced Nursing, 63(5), 527-534.

Fodor, J. A. (1983). The modularity of mind: An essay on faculty psychology: MIT press.

Fosha, D. (2001). The dyadic regulation of affect. Journal of Clinical Psychology, 57(2), 227-242.

Garrison, D. R., Anderson, T., \& Archer, W. (1999). Critical inquiry in a text-based environment: Computer conferencing in higher education. The internet and higher education, 2(2), 87-105. 
Garrison, D. R., Cleveland-Innes, M., \& Fung, T. S. (2010). Exploring causal relationships among teaching, cognitive and social presence: Student perceptions of the community of inquiry framework. The internet and higher education, 13(1), 31-36.

Geller, S., \& Greenberg, L. (2002). Therapeutic Presence: Therapists' experience of presence in the psychotherapy encounter/Therapeutische Präsenz: Erfahrungen von Therapeuten mit Präsenz in der psychotherapeutischen Begegnung/La Presencia Terapéutica: La Experiencia de la Presencia que Viven los Terapeutas en el Encuentro Psicoterapéutico. Person-Centered \& Experiential Psychotherapies, 1(1-2), 71-86.

Geller, S., \& Greenberg, L. (2012). Therapeutic presence: A mindful approach to effective therapy: American Psychological Association.

Geller, S., Greenberg, L., \& Watson, J. C. (2010). Therapist and client perceptions of therapeutic presence: The development of a measure. Psychotherapy Research, 20(5), 599-610.

Geller, S., \& Porges, S. W. (2014). Therapeutic presence: Neurophysiological mechanisms mediating feeling safe in therapeutic relationships. Journal of Psychotherapy Integration, 24(3), 178.

Geller, S., Pos, A., \& Colosimo, K. (2012). Therapeutic presence: A common factor in the provision of effective psychotherapy. Society for Psychotherapy Integration, 47, 6-13.

Germain, V., Marchand, A., Bouchard, S., Guay, S., \& Drouin, M.-S. (2010). Assessment of the therapeutic alliance in face-to-face or videoconference treatment for posttraumatic stress disorder. Cyberpsychology, Behavior, and Social Networking, 13(1), 29-35.

Granick, J. L. (2011). Transpersonal aspects of therapists' presence: What do clients experience? (Doctorate ), Institute of Transpersonal Psychology, Palo Alto, California.

Greenberg, L., \& Geller, S. (2001). Congruence and therapeutic presence. Rogers' therapeutic conditions: Evolution, theory and practice, 1, 131-149.

Gunawardena, C. N., \& Zittle, F. J. (1997). Social presence as a predictor of satisfaction within a computermediated conferencing environment. American journal of distance education, 11(3), 8-26.

Hagerty, B. M., Lynch-Sauer, J., Patusky, K. L., \& Bouwsema, M. (1993). An emerging theory of human relatedness. IMAGE-INDIANAPOLIS-, 25, 291-291.

Hanley, T., \& Reynolds, D. (2009). Counselling Psychology and the internet: A review of the quantitative research into online outcomes and alliances within text-based therapy. Counselling Psychology Review, 24(2), 4-13.

Hassenstab, J., Dziobek, I., Rogers, K., Wolf, O. T., \& Convit, A. (2007). Knowing what others know, feeling what others feel: a controlled study of empathy in psychotherapists. The Journal of nervous and mental disease, 195(4), 277-281.

Hayes, J. A., Gelso, C. J., \& Hummel, A. M. (2011). Managing countertransference. Psychotherapy, 48(1), 88.

Hayes, J. A., \& Vinca, M. A. (2011). Therapist presence and its relationship to empathy, session depth, and symptom reduction. Paper presented at the the meeting of the Society for Psycho - therapy Research, Bern, Switzerland.

Hoffman, M. L. (1984). Interaction of affect and cognition in empathy. Emotions, cognition, and behavior, 103-131.

Huang, M. P., \& Alessi, N. E. (1999). Presence as an emotional experience. Studies in health technology and informatics, 148-153.

Hutchins, H. M. (2003). Instructional immediacy and the seven principles: Strategies for facilitating online courses. Online Journal of Distance Learning Administration, 6(3).

Hutchison, A. N., \& Gerstein, L. H. (2012). What's in a face? Counseling trainees' ability to read emotions. Training and Education in Professional Psychology, 6(2), 100-112. doi: 10.1037/a0028807

IJsselsteijn, W. (2002). Elements of a multi-level theory of presence: Phenomenology, mental processing and neural correlates. Proceedings of PRESENCE, 2002, 245-259.

Johnson, S. M. (2012). Practice of Emotionally Focused Couple Therapy: Creating Connection: Routledge.

Johnsson, R., \& Stenlund, G. (2010). The affective dimension of alliance in transactional analysis psychotherapy. International Journal of Transactional Analysis Research, 1(1).

Kang, M., Kim, J., \& Kang, J. (2008). Relationships among Self-efficacy, Metacognition, Cognitive presence, Flow, and Learning Outcomes in web-based PBL. Paper presented at the Society for Information Technology \& Teacher Education International Conference. 
Kang, M., Kim, S., Choi, H., \& Park, S. (2007). Validating an Emotional Presence Scale to Measure Online Learners' Engagement. Paper presented at the World Conference on E-Learning in Corporate, Government, Healthcare, and Higher Education.

Kang, M., Kim, S., \& Park, S. (2007). Developing Emotional Presence Scale for Measuring Students' Involvement during e-Learning process. Paper presented at the World Conference on Educational Multimedia, Hypermedia and Telecommunications.

Kanuka, H., \& Garrison, D. R. (2004). Cognitive presence in online learning. Journal of Computing in Higher Education, 15(2), 21-39.

King, R., Bambling, M., Reid, W., \& Thomas, I. (2006). Telephone and online counselling for young people: A naturalistic comparison of session outcome, session impact and therapeutic alliance. Counselling and Psychotherapy Research, 6(3), 175-181.

Kleinke, C. L. (1986). Gaze and eye contact: a research review. Psychological bulletin, 100(1), 78.

Kostovich, C. T. (2012). Development and psychometric assessment of the presence of nursing scale. Nursing science quarterly, 25(2), 167-175.

Kreijns, K., Kirschner, P. A., Jochems, W., \& Van Buuren, H. (2011). Measuring perceived social presence in distributed learning groups. Education and Information Technologies, 16(4), 365-381.

Kurtz, R. R., \& Grummon, D. L. (1972). Different approaches to the measurement of therapist empathy and their relationship to therapy outcomes. Journal of consulting and clinical psychology, 39(1), 106.

Lee, R. M., Draper, M., \& Lee, S. (2001). Social connectedness, dysfunctional interpersonal behaviors, and psychological distress: Testing a mediator model. Journal of Counseling Psychology, 48(3), 310.

Lehman, R. (2006). The role of emotion in creating instructor and learner presence in the distance education experience. Journal of Cognitive Affective Learning, 2(2), 12-26.

Machado, P. P. P., Beutler, L. E., Greenberg, L., Machado, P. P. P., Beutler, L. E., \& Greenberg, L. S. (1999). Emotion recognition in psychotherapy: Impact of therapist level of experience and emotional awareness. Journal of Clinical Psychology, 55, 39-57. doi: 10.1002/(SICI)10974679(199901)55:1<39::AID-JCLP4>3.0.CO2-V

Manstead, A. S., Lea, M., \& Goh, J. (2011). Facing the future: Emotion communication and the presence of others in the age of video-mediated communication. In A. Kappas, \& Krämer, N. (Ed.), Face-to-face communication over the internet: Issues, research, challenges (pp. 144-175). Cambridge: UK: Cambridge University Press.

Martin, D. J., Garske, J. P., \& Davis, M. K. (2000). Relation of the therapeutic alliance with outcome and other variables: a meta-analytic review. Journal of consulting and clinical psychology, 68(3), 438.

Mathews, A., Fox, E., Yiend, J., \& Calder, A. (2003). The face of fear: Effects of eye gaze and emotion on visual attention. Visual Cognition, 10(7), 823-835.

Mayer, J. D., Caruso, D. R., \& Salovey, P. (1999). Emotional intelligence meets traditional standards for an intelligence. Intelligence, 27(4), 267-298.

Mayer, J. D., Roberts, R. D., \& Barsade, S. G. (2008). Human abilities: Emotional intelligence. Annu. Rev. Psychol., 59, 507-536.

Mayer, J. D., \& Salovey, P. (2007). Mayer-Salovery-Caruso Emotional Intelligence Test(MSCEIT) user's manua. Toronto: Multi-Health Systems Incorporated.

Mehrabian, A. (1967). Attitudes inferred from neutral verbal communications. Journal of consulting psychology, 31(4), 414.

Mehrabian, A. (1981). Silent messages : implicit communication of emotions and attitudes. Belmont, Calif.: Wadsworth Pub. Co.

Mehrabian, A., \& Epstein, N. (1972). A measure of emotional empathy1. Journal of personality, 40(4), 525543.

Melnechenko, K. L. (2003). To make a difference: Nursing presence. Nursing forum, 38, 18.

Miclea, M., Miclea, Ş., Ciuca, A. M., \& Budau, O. (2010). Computer-mediated psychotherapy. Present and prospects. A developer perspective. Cognition, Brain, Behavior: An Interdisciplinary Journal, 14, 185-208.

Minicucci, D. (1997). A review and synthesis of the literature: the use of presence in the nursing care of families. The Journal of the New York State Nurses' Association, 29(3-4), 9-15.

Minzenberg, M. J., Poole, J. H., \& Vinogradov, S. (2006). Social-emotion recognition in borderline personality disorder. Comprehensive Psychiatry, 47(6), 468-474. doi: http://dx.doi.org/10.1016/j.comppsych.2006.03.005 
Myers, D., \& Hayes, J. A. (2006). Effects of therapist general self-disclosure and countertransference disclosure on ratings of the therapist and session. Psychotherapy: Theory, Research, Practice, Training, 43(2), 173.

Newton, D. A., Burgoon, J. K., \& Cahn, D. D. (1990). Nonverbal conflict behaviors: Functions, strategies, and tactics. Intimates in conflict: A communication perspective, 77-104.

Norcross, J.C., \& Wampold, B.E. (2011) Evidence-based therapy relationship: Research conclusions and clinical practices. Psychotherapy, 48(1), 98_102. doi: 10.1037/a0022161.

Nunez, D. (2007). A capacity limited, cognitive constructionist model of virtual presence. (Unpublished doctoral dissertation), University of Cape Town South Africa. , Retrieved Octobor 10, 2015, from http://people.cs.uct.ac.za/ edwin/MyBib/2007-nunez-thesis.pdf.

Nunez, D., \& Blake, E. (2001). Cognitive presence as a unified concept of virtual reality effectiveness. Proceedings of the 1st international conference on Computer graphics, virtual reality and visualisation, 115-118.

Pell, M. D., Jaywant, A., Monetta, L., \& Kotz, S. A. (2011). Emotional speech processing: Disentangling the effects of prosody and semantic cues. Cognition \& Emotion, 25(5), 834-853.

Pelling, N. J. (2009). The use of email and the Internet in counselling and psychological service: what practitioners need to know. Counselling, Psychotherapy and Health.

Pemberton, B. K. (1977). The presence of the therapist. (Doctoral Dissertation), Georgia State University.

Rey, B., Alcañiz, M., Lozano, J. A., Baños, R., Botella, C., Lasso, N., \& Osma, J. (2004). Emotionally controlled virtual environments: A new tool for enhancing presence through media content manipulation. Seventh Anuual International Workshop Presence, 174-181. Valencia, Spain: UPV.

Rigoulot, S., \& Pell, M. D. (2012). Seeing emotion with your ears: emotional prosody implicitly guides visual attention to faces. PLoS ONE, 7(1), e30740.

Rispens, S., Greer, L. L., \& Jehn, K. A. (2007). It could be worse: A study on the alleviating roles of trust and connectedness in intragroup conflicts. International journal of conflict management, 18(4), 325-344.

Riva, G., Mantovani, F., Capideville, C. S., Preziosa, A., Morganti, F., Villani, D., . . . Alcañiz, M. (2007). Affective interactions using virtual reality: the link between presence and emotions. CyberPsychology \& Behavior, 10(1), 45-56.

Robbins, A. (1997). Therapeutic presence: Bridging expression and form: Jessica Kingsley Publishers.

Robinson, P., \& Serfaty, M. (2008). Getting better byte by byte: a pilot randomised controlled trial of email therapy for bulimia nervosa and binge eating disorder. European Eating Disorders Review, 16(2), 8493.

Rogers, C. (2000). Interview with Carl Rogers on the use of the self in therapy. The use of self in therapy, 2938.

Salovey, P., Brackett, M. A., \& Mayer, J. D. (2004). Emotional intelligence: Key readings on the Mayer and Salovey model: NPR Inc.

Salovey, P., \& Mayer, J. D. (1989). Emotional intelligence. Imagination, cognition and personality, 9(3), 185211.

Schwartz, R., \& Pell, M. D. (2012). Emotional Speech Processing at the Intersection of Prosody and Semantics. PLOS ONE, 7(10), e47279.

Shea, P., \& Bidjerano, T. (2009). Community of inquiry as a theoretical framework to foster "epistemic engagement" and "cognitive presence” in online education. Computers \& Education, 52(3), 543-553.

Short, J., Williams, E., \& Christie, B. (1976). The Social Psychology of Telecommunications: Wiley.

Simone, M. (1992). The human act of caring: A blueprint for the health professions. Canadian Hospital Association Press, Ottawa: Canadian Hospital Association.

Simpson, S. G., \& Reid, C. L. (2014). Therapeutic alliance in videoconferencing psychotherapy: A review. Australian Journal of Rural Health, 22(6), 280-299.

Smith, A. (2006). Cognitive Empathy and Emotional Empathy in Human Behavior and Evolution. Psychological Record, 56(1), 3.

Stein, D. M., \& Lambert, M. J. (1984). On the relationship between therapist experience and psychotherapy outcome. Clinical Psychology Review, 4(2), 127-142.

Sussman, R. (2004). Counseling over the Internet: Benefits and Challenges in the Use of New Technologies. Alexandria, VA: American Counseling Association.

Townsend, K. C., \& McWhirter, B. T. (2005). Connectedness: A review of the literature with implications for counseling, assessment, and research. Journal of Counseling and Development: JCD, 83(2), 191. 
Tu, C.-H., \& McIsaac, M. (2002). The relationship of social presence and interaction in online classes. The American journal of distance education, 16(3), 131-150.

Vanden Abeele, M., Roe, K., \& Pandelaere, M. (2007). Construct Validation of the Concepts Social Presence, Emotional Presence and Connectedness. Presence 2007, 215-224.

Varcarolis, E. M., \& Varcarolis, E. (2002). Developing therapeutic relationships. Foundations of psychiatric mental health nursing: A clinical approach, 4th edn., EM Varcarolis. WB Saunders, Philadelphia, 220-239.

Walther, J. (2011). Theories of computer-mediated communication and interpersonal relations. The handbook of interpersonal communication, 4, 443-479.

Walther, J., \& Tidwell, L. C. (1995). Nonverbal cues in computer- mediated communication, and the effect of chronemics on relational communication. Journal of Organizational Computing and Electronic Commerce, 5(4), 355-378.

Wang, M., \& Kang, M. (2006). Cybergogy for engaged learning: A framework for creating learner engagement through information and communication technology Engaged learning with emerging technologies (pp. 225-253): Springer.

Wiener, M., \& Mehrabian, A. (1968). Language within language: Immediacy, a channel in verbal communication: Ardent Media.

Wirth, W., Hartmann, T., Böcking, S., Vorderer, P., Klimmt, C., Schramm, H., . . Gouveia, F. R. (2007). A process model of the formation of spatial presence experiences. Media Psychology, 9(3), 493-525.

Wirth, W., Hofer, M., \& Schramm, H. (2012). The role of emotional involvement and trait absorption in the formation of spatial presence. Media Psychology, 15(1), 19-43.

Witmer, B. G., \& Singer, M. J. (1998). Measuring presence in virtual environments: A presence questionnaire. Presence: Teleoperators and virtual environments, 7(3), 225-240.

Zajonc, R. B. (1980). Feeling and thinking: Preferences need no inferences. American psychologist, 35(2), 151.

Zhang, X., Yu, H., \& Barrett, L. F. (2014). How does this make you feel? A comparison of four affect induction procedures. Emotion Science, 5, 689. 